\title{
UNITY IN VARIETY. EMPLOYMENT DYNAMICS AND SPECIALISATION PROFILES OF MEDIUM-SIZED TOWNS IN THE ASTI-ROVIGO AREA, ITALY (2001-2017)
}

\author{
Maria Antonietta Clerici 10 \\ Department of Architecture and Urban Studies, Polytechnic University of Milan
}

Manuscript received: September 26, 2020

Revised version: November 10, 2020

\begin{abstract}
ClerICI M.A., 2020. Unity in variety. Employment dynamics and specialisation profiles of medium-sized towns in the Asti-Rovigo area, Italy (2001-2017). Quaestiones Geographicae 39(4), Bogucki Wydawnictwo Naukowe, Poznań, pp. 5-22. 6 tables, 5 figs.

AвSTRACT: We still know relatively little about the processes of economic transformation in medium-sized towns, which are the cornerstone of the settlement system of many rural areas, together with small towns. This paper considers a group of 39 towns in Northern Italy, located in the area between Asti and Rovigo. Using data from the Italian National Institute of Data Statistics (ISTAT), we investigated the dynamics of the number of the employed at businesses in the periods of 2001-2011 and 2012-2017, the different specialisations of the towns and their ability to attract employees within the respective employment areas. Locally differentiated performance and evolutionary trajectories are evident, preventing us from being able to think of medium-sized (but also small) towns as a coherent whole. It is also clear how the drive towards centralising employees in towns increased following the Great Recession.
\end{abstract}

KEYWORDS: medium-sized towns, small towns, rural areas, employment, economic specialisation, employment areas

Corresponding author: Maria Antonietta Clerici, Polytechnic University of Milan, School of Architecture Urban Planning Construction Engineering, Department of Architecture and Urban Studies, Piazza Leonardo da Vinci 32, 20133 Milan, Italy; e-mail:maria.clerici@polimi.it

\section{Introduction}

Globalisation was the triumph of cities (Glaeser 2011). However, metropolitan areas - key hubs for the competitiveness of national economies and on the front line in the quest for a sustainable development model - have attracted the most attention from academics and the mass media. Urban studies of recent decades, dominated by a metrocentric perspective, have shown very little interest in medium-sized towns (MSTs), despite the fact that, along with small towns housing large populations and contributing to the reinforcement of a polycentric spatial structure, they pave the way for fewer regional imbalances (Bell, Jayne 2009; Demazière 2017). The importance of MSTs and small towns is even more evident in the European Union (EU): non-metropolitan regions, which can rely only on these kinds of towns, attract $41 \%$ of the population and generate $32 \%$ of the total GDP (Eurostat 2016). They have performed well, even in the face of the Great Recession, contradicting the 'bigger is better' narrative diffused by the New Economic Geography (Camagni et al. 2015; David et al. 2013; Dijkstra et al. 2013; Dijkstra et al. 2015).

The development dynamics of MSTs and their specific role in urban networks are a research

\section{sciendo}


question that is still relevant and under discussion to this day. It is not easy to study these towns, given their diverse settlement situations, socio-economic profiles and evolutionary trajectories (ESPON 2014). Their 'regional capitals' are different from those of large cities and this inevitably shapes their destiny. We generally associate MSTs with a better quality of life, a strong sense of identity, greater social cohesion and care for the environment. However, they are also caught in the cross-fire. On the one hand, they compete with the metropolitan centres, magnets for creativity, culture and knowledge, which play a key role in the current economic development model. On the other, they grapple with the dynamic nature of small towns, which have gained greater importance (including in politics) in urban networks, thanks to their ability to attract decentralised housing and businesses away from the main hubs. Moreover, the rationalisation of public services, in connection with the austerity policies launched by national governments after the 2008 economic crisis, penalised many MSTs, which were affected by a decline in employment in activities of historic importance for them. However, MSTs cannot be considered as a unitary category, with a destiny linked solely to their intermediate position in the urban system. Size poses constraints, but we need to consider the links each city has to the local community, their location in more or less dynamic regions, with a specific production structure, as well as the web of relations that connects each town to its geographical surroundings (Cattan, Saint-Julien 1999; Adam 2006; Servillo et al. 2017).

Against this general backdrop, this essay considers a group of 39 towns in Northern Italy, located in the area between Asti and Rovigo, delving into their employment dynamics in the period of 2001-2017. The area lies across four of the most developed regions on a national and European scale: Piedmont, Lombardy, EmiliaRomagna and Veneto. It is a predominantly flat area, with a low population density, home to 24 MSTs and 15 small towns, all centres of employment areas (Sistemi locali del lavoro).

Studies on MSTs have not traditionally been carried out in Italy as they have in countries such as France and Spain, where, since the 1970s, MSTs have become a specific area of study (and have even inspired ad hoc policies in France).
However, they have received increasing attention in recent years, primarily in response to a political debate focusing on metropolitan areas (established in 2014) and inland areas, both recipients of significant public funding (IFEL 2019; Mecenate 90 2020). MSTs have supported Italy's economic development - especially in the regions of the north-east-centre - and have also demonstrated their viability over recent years. According to Burgalassi et al. (2016), between 2001 and 2011, they drove the growth of national employment more than the large cities did. Faggian et al. (2018) also highlighted the resistance to the 2009-2010 recession of many employment areas hinged on MSTs. However, we cannot make generalisations: we need to examine individual regions.

The paper investigates the role of MSTs in territorial development processes, considering the case of a vast rural area of the Po Valley megalopolis that is subordinate to large urban agglomerations in that area (Mainardi 1997; Turri 2000). It focuses on job dynamics in the private sector, a primary indicator of the viability of cities. The evolutionary trajectories of the medium-sized and small towns dotted throughout the study area are investigated in a period of hardship for the Italian economy (2001-2017), during which the gaps between territories widened, even in Italy's most developed regions. More specifical$1 y$, there are three research questions. Are there any differences in performance to the benefit of MSTs, and are such differences long-lasting? Are the towns more closely linked to industry - of which there are many in the study area - grappling with greater hardship, as is the case in other countries? Are the towns taken into consideration major centres within their respective employment areas?

Cities are the driving force of macro-regions, but we must not overlook what is happening in smaller towns. We need to study the characteristics and evolutionary trajectories of the individual types of towns making up the macro-regions, because these affect overall economic performance and regional cohesion. The paper also calls into question the idea, still prevalent in Italy, that MSTs are a unitary category. Even if we consider only provincial capitals that are not metropolitan cities established in 2014, the towns we find (93) are very diverse in terms of production structure, 
performance and local networks of relations. Unfortunately, all this is sidelined in the current debate. Instead, there is mention of a unitary policy supporting the club of MSTs, in a bid to offset the strength of metropolitan centres (IFEL 2019).

The paper is divided into two parts. Part one reflects on the importance of MSTs in the settlement system and their diverse profiles, which pave the way for different evolutionary trajectories. Part two is the case study. This focuses on 39 cities, selected using a population criterion. The analysis concerns not only MSTs but also small towns to gain a better understanding of the specific behaviour of MSTs. We will address three research questions: employee dynamics in local units (private business) in the periods of 20012011 and 2012-2017; specialisation profiles of the towns and how they have changed over time; reorganisation of relations on a local scale, between towns and their respective local surroundings, corresponding to the employment areas. The recent phase (2012-2017), which suffered the effects of a long economic recession, marks a break with the past, in terms of behaviour, for each of the three topics discussed.

\section{A heterogeneous group of cities}

It is not easy to single out MSTs from the urban continuum. They are 'unidentified real objects' (Brunet 1997: 188): the existence of an intermediate layer in the urban structure is undeniable, but its delimitation is ambiguous, even within a single town or region. Multiple criteria may be used - population, functional, morphological - and very different parameters and constraints can be established for each of these: much depends on the scale of analysis, the density of the settlement structure and the arbitrary choices of academics (Santamaria 2000; Marques da Costa 2002; ESPON 2006). Despite the uncertain definition, the importance of MSTs is widely recognised. They are poles in local labour markets, offering a wide range of public and private services, serving as drivers for development for the surrounding areas, a role which is enhanced in remote regions (Mayfield et al. 2005; Vaishar, Zapletalová 2009). MSTs bridge the gap between local and global, regulate urban/rural balance and are the cornerstones of a polycentric (more balanced) regional structure. All this is also recalled in the Lleida Declaration (1999) and Chefchaouen Declaration (2018), originating from international congresses $^{1}$ aimed at drawing attention to the roles and potential of a group of towns that are generally overlooked by decision makers.

The focus on polycentricity in EU territorial policies, as a means of mitigating competitiveness and cohesion, has resulted in growing attention being paid to MSTs, even if policies directly supporting them have been lacking. The Green Paper on territorial cohesion (EC 2008) underlines how these towns create diversity in the EU - a value to be preserved - and are fundamental for balanced territorial development. This is especially the case in intermediate and rural regions, where they provide services and jobs that contribute to a good quality of life locally, stemming depopulation. The Riga Declaration (2015) ${ }^{2}$, a key step towards launching a European urban agenda, also insists on the importance of medium-sized (and small) towns for territorial cohesion, underlining how, despite their great potential, they often have to face a difficult socio-economic transition due to globalisation, which has benefited large cities.

Regardless of all this, MSTs form a heterogeneous world. The first important factor of diversity concerns their geographical location. At European level, Kunzmann (2010) differentiates between MSTs located in metropolitan areas, those positioned between several metropolitan areas, in rural peripheral areas and near borders (national and European). According to the author, these four settlement patterns affect the functional specialisation profiles of the towns and their evolutionary dynamics. On a global scale, the UCLG (2017) divides intermediary cities (50,000-1 million inhabitants) into three main types: subnational centres (regional cities), decentralised networks of cities (clustered cities) and clusters of cities linked to infrastructural roads, including transnational roads (corridor cities). In studies on individual countries, it is

International congress on intermediate cities, architecture and urban planning (Lleida, 15-18 February 1999) and First World Forum on intermediary cities (Chefchaouen, 5-7 July 2018).

2 Outcome of the Informal Meeting of EU Ministers Responsible for Territorial Cohesion and Urban Matters (Riga, 10 June 2015). 
common to find a distinction between MSTs located in urban regions, inland areas (rural) and coastal areas (Ganau Casas, Vilagrasa Ibarz 2003; De Roo 2007). The structure with respect to the local administrative geography is also important. In Spain, examining the networks of provinces, Escudero Gómez et al. (2019) identify cities that are monocentric (just one MST functioning as the administrative centre), bi-centric, and polycentric and connected to metropolitan areas. Commuting flows are often taken into account to assess the ability of cities to dominate larger or smaller territorial surroundings. In this regard, reflecting on the case of France, Nadou (2010) identifies three types of MSTs: 1) far away and autonomous from large urban centres and therefore able to lay claim to their own area of influence; 2) located within the sphere of influence of a city; 3) positioned in an intermediate situation between the previous two points, i.e. not fully autonomous from a city, but with its own micro-regions. Other studies, on the other hand, propose a distinction between independent, isolated, dependent and interdependent towns (Jones et al. 2009; Bolton, Hildreth 2013). The first two situations refer to towns that are capable of generating their own labour market, which is strong or weak, respectively, in terms of the volume of flows attracted. In both of these cases, the labour markets do not interact with those of large cities. They are, therefore, autonomous centres. Dependent MSTs fall within the labour market centred on a big city, while interdependent ones succeed in laying claim to their own catchment area, despite finding themselves in the same situation. The TOWN study (ESPON 2014; Sýkora, Mulíček 2017) also focuses extensively on the web of relationships on a local scale, identifying three typical spatial configurations of MSTs: 1) agglomerations in metropolitan areas; 2) willing to form a polycentric network in areas with a low level of urbanisation or in any case outside large urban agglomerations; 3 ) isolated in rural peripheral areas and characterised by a high level of autonomy. In addition to the problem of describing them, the position of the settlement system is also important, as it influences how MSTs grow: those located in inland areas and those most isolated from large urban centres and infrastructural corridors encounter the greatest difficulties (Escudero Gómez, Somoza Medina 2010; Garrido Cumbrera et al. 2016). The effects of proximity to the large city are mixed, on the other hand. While significant population and employment growth is possible, often linked to the exploitation of 'borrowed size' (Meijers et al. 2016; Kaufmann, Wittwer 2019), the pull of the city can also put surrounding MSTs at an unfair disadvantage, limiting their functional centrality. This 'agglomerations shadow' is common in Eastern European countries, where MSTs located in the sphere of influence of the capitals show persistent under-provision of functions compared to more peripheral centres of the same size, despite attracting the population (Czapiewski et al. 2016).

MST case studies are just as diverse from a functional profile point of view. Henderson (1997) distinguishes between centres focusing on industry and those focusing on services. In the former case, the production system is often very specialised and this can become a problem: a crisis in the dominant sector can throw the town into a spiral of decline that is difficult to halt. The TOWN study (ESPON 2014; Hamdouch et al. 2017a) looks at the importance of the residential economy and productive economy ${ }^{3}$; in addition to cities that are specialised in one way or another, there are those with a mixed profile and a high percentage of people working in creative businesses. Studies on individual countries go into greater detail, highlighting the high variety of specialisation of MSTs (Bolton, Hildreth 2013; Cox, Longlands 2016; Meili, Mayer 2017). If we investigate the relationship between functional profiles and development dynamics, it is clear how MSTs, where manufacturing, construction and lower-skilled service sectors are dominant, face greater hardship in the long-term, with performance deteriorating even further in the face of the Great Recession (Erickcek, McKinney 2006; Clayton, Morris 2010; Champion, Townsend 2013; Hamdouch et al. 2017a; CGET 2018).

Structural constraints relating to the small size, in terms of smaller agglomeration economies, positioning in the urban network and functional specialisation are all factors influencing the evolutionary trajectories of MSTs. However, much also depends on policy makers, on their

\footnotetext{
The former consists of businesses that meet the needs of local users (residents, commuters, tourists); the latter includes the production of goods and provision of services intended predominantly for the external market.
} 
ability to attract investments and capacity to create networks on various scales to offset the attraction of large cities, setting value on local 'territorial capitals' (Knox, Mayer 2013; Hamdouch et al. 2017b; Lazzeroni 2020).

\section{Study area: Selecting the towns and essential characteristics}

In Italy, the settlement system of expansive territories is hinged on small and medium-sized towns. This is also the case in the study area: the quadrant of the Po Valley megalopolis between Asti and Rovigo. Its position is unique: it is a cluster of nine provinces positioned between the most densely populated areas of the Po Valley megalopolis, located in a line along the foothill motorway (Turin to Venice) and the 'via Emilia' road. The geographer Turri (2000) describes this area as the 'green heart' of the Po Valley megalopolis. The landscapes change considerably from west to east as we pass through four regions (Piedmont, Lombardy, Emilia-Romagna and Veneto). However, this territorial area boasts its own intrinsic unitarity: it is a patchwork of intermediate regions - according to the OECD classification ${ }^{4}$. The former strada statale 10 (highway) passes through it. This road was opened in 1928 and is the main transport route in the Lower valley. The Po River also determines the settlement patterns, landscapes and the economy of the area. It currently accounts for around 3 million inhabitants and 850,000 employees (13\% and $10 \%$ respectively of the four reference regions). The share of municipalities with fewer than 5,000 inhabitants is overwhelming $(85 \%$ of the total in 2019). At provincial level, the territorial density fluctuates between 120 inhabitants $/ \mathrm{km}^{2}$ (Alessandria, Piacenza) and 294 inhabitants $/ \mathrm{km}^{2}$ (Lodi): these values are significantly lower than those recorded along the 'via Emilia' and especially along the foothill stretch, where a peak of 2,000 inhabitants $/ \mathrm{km}^{2}$ is reached in the provinces of Milan and Monza-Brianza.

To identify MSTs within a network of 845 municipalities (as at 2019), we used a population

In other words, 15 to $50 \%$ of the total population lives in municipalities (LAU2) with low population density $\left(<150\right.$ inhabitants $\left./ \mathrm{km}^{2}\right)$. criterion, taking into consideration those towns falling within the 20,000-200,000-inhabitant range in at least one year of the 2001-2019 period. As Kunzmann (2010) recalls, these values are commonly used in the European context. While identifying MSTs based on the functions they perform, Cori et al. (1978) also demonstrated how in Northern Italy, MSTs predominantly fall within this size category. In this way, 24 MSTs can be identified in the study area. We then checked whether these are employment area centroids, since we consider this to identify a role as a functional centre for ample or small surroundings. Using the geography of employment areas in 2011, all the towns selected have this status, apart from Cento and Argenta. However, the aforesaid cities did have this status in $2001^{5}$. Towns of the size considered do not always 'control' their own employment area. This characteristic is not found, for instance, in the Milan area: here, Monza and Rho, which are considered MSTs (Lemmi 2012) due to the number of inhabitants they have and the type of functions they perform, come under the employment area of Milan ${ }^{6}$. Overall, we singled out the nine cities that in addition to being employment area centroids are also provincial capitals. A further 15 municipalities are centres of employment areas (as at 2011), but with a population of fewer than 20,000 inhabitants: these were also taken into account in the study. We will therefore follow the dynamics of three groups of towns (Table 1): provincial capital MSTs (9), other MSTs (15) and small towns (15). These account for $28 \%, 17 \%$ and $7 \%$ of the total number of persons employed in the study area respectively (in 2017). With respect to what was discussed earlier, we will be focusing on specific cases: towns located in rural regions and towns that are autonomous from metropolitan centres, with the exception of those nearest to Milan, which, with its far-reaching influence, limits the supremacy of the surrounding MSTs, whether or not these are provincial capitals. An analysis of daily travel for work purposes (ISTAT data as at 2011) shows how many MSTs in this area have busy links with Milan, facilitated by an efficient public transport

Reference will be made to their employment areas as at 2001.

6 Monza is the provincial capital, with 124,051 inhabitants; Rho has 50,602 inhabitants (ISTAT data, 2019). 
network (Underground railway link). Thirty percent of commuting flows from the municipalities of Pavia, Vigevano and Lodi are bound for the capital of Lombardy. High values (10-15\%) are also found for Voghera, Crema, Cremona and
Piacenza. Moreover, the Milan metropolitan area stretches well beyond the provincial administrative borders: an excellent example of how geographical images and perimeters set by law do not coincide (Bartaletti 2015).

Table 1. The 39 towns analysed: resident population and employees at local units $(2001,2017,2019)$.

\begin{tabular}{|c|c|c|c|c|c|c|c|c|}
\hline \multirow[t]{2}{*}{ Type } & \multirow[t]{2}{*}{ Province } & \multirow[t]{2}{*}{ Municipality } & \multirow{2}{*}{$\begin{array}{c}\text { Inhabitants, } \\
2019\end{array}$} & \multirow{2}{*}{$\begin{array}{c}\text { Inhabitants / } \\
\text { Kmq., } 2019\end{array}$} & \multirow{2}{*}{$\begin{array}{c}\text { Employees, } \\
2017\end{array}$} & \multirow{2}{*}{$\begin{array}{c}\text { Employees/ } \\
\text { 1,000 inhab., } \\
2017\end{array}$} & \multicolumn{2}{|c|}{$\begin{array}{l}\% \text { industry } \\
\text { employees }\end{array}$} \\
\hline & & & & & & & 2001 & 2017 \\
\hline $\mathrm{A}$ & 1 & Asti & 76,026 & 502 & 22,119 & 290 & 36.0 & 25.8 \\
\hline $\mathrm{A}$ & 2 & Alessandria & 93,631 & 460 & 29,705 & 316 & 33.8 & 26.6 \\
\hline $\mathrm{A}$ & 3 & Pavia & 73,086 & 1,156 & 24,031 & 330 & 25.0 & 12.5 \\
\hline $\mathrm{A}$ & 4 & Lodi & 45,872 & 1,109 & 16,093 & 356 & 26.8 & 20.3 \\
\hline A & 5 & Cremona & 72,680 & 1,031 & 25,018 & 347 & 36.7 & 28.7 \\
\hline $\mathrm{A}$ & 6 & Mantua & 49,403 & 774 & 24,635 & 502 & 32.3 & 20.1 \\
\hline $\mathrm{A}$ & 7 & Piacenza & 103,942 & 879 & 42,651 & 414 & 27.7 & 20.4 \\
\hline A & 8 & Ferrara & 132,052 & 326 & 40,968 & 310 & 32.1 & 22.5 \\
\hline $\mathrm{A}$ & 9 & Rovigo & 51,104 & 470 & 18,649 & 365 & 38.1 & 28.5 \\
\hline B & 2 & Acqui Terme & 19,604 & 589 & 5,887 & 300 & 32.5 & 24.6 \\
\hline B & 2 & Casale Monferrato & 33,725 & 391 & 11,810 & 347 & 41.8 & 30.0 \\
\hline $\mathrm{B}$ & 2 & Novi Ligure & 28,286 & 512 & 9,085 & 322 & 39.3 & 37.1 \\
\hline B & 2 & Tortona & 27,291 & 276 & 12,545 & 460 & 36.3 & 27.8 \\
\hline B & 2 & Valenza & 18,634 & 384 & 8,671 & 461 & 69.6 & 62.3 \\
\hline B & 3 & Vigevano & 63,426 & 780 & 18,034 & 286 & 50.5 & 34.5 \\
\hline B & 3 & Voghera & 39,365 & 621 & 10,341 & 263 & 35.9 & 27.3 \\
\hline B & 5 & Crema & 34,487 & 999 & 13,436 & 392 & 29.2 & 16.0 \\
\hline B & 6 & Castiglione delle Stiviere & 23,704 & 564 & 11,149 & 473 & 59.0 & 42.4 \\
\hline B & 6 & Suzzara & 21,313 & 349 & 8,842 & 418 & 66.9 & 49.2 \\
\hline B & 6 & Viadana & 20,154 & 194 & 7,141 & 356 & 57.1 & 47.5 \\
\hline B & 8 & Argenta & 21,429 & 69 & 4,890 & 227 & 59.9 & 36.2 \\
\hline $\mathrm{B}$ & 8 & Cento & 35,474 & 548 & 11,081 & 312 & 56.0 & 43.6 \\
\hline B & 8 & Comacchio & 22,114 & 78 & 6,597 & 297 & 29.9 & 15.0 \\
\hline B & 9 & Adria & 19,347 & 171 & 4,702 & 242 & 46.2 & 31.8 \\
\hline $\mathrm{C}$ & 1 & Canelli & 10,411 & 444 & 4,119 & 395 & 58.9 & 52.2 \\
\hline $\mathrm{C}$ & 1 & Nizza Monferrato & 10,290 & 339 & 2,875 & 279 & 35.9 & 24.0 \\
\hline $\mathrm{C}$ & 2 & Ovada & 11,299 & 319 & 3,442 & 303 & 37.5 & 31.0 \\
\hline $\mathrm{C}$ & 3 & Stradella & 11,578 & 615 & 3,806 & 327 & 30.3 & 22.6 \\
\hline $\mathrm{C}$ & 3 & Sannazzaro de' Burgondi & 5,414 & 232 & 3,000 & 553 & 66.5 & 52.4 \\
\hline $\mathrm{C}$ & 5 & Casalmaggiore & 15,445 & 239 & 4,898 & 318 & 54.2 & 46.4 \\
\hline $\mathrm{C}$ & 6 & Asola & 10,056 & 137 & 3,450 & 343 & 56.8 & 36.6 \\
\hline $\mathrm{C}$ & 6 & Castel Goffredo & 12,733 & 300 & 5,010 & 397 & 72.7 & 55.5 \\
\hline $\mathrm{C}$ & 6 & Poggio Rusco & 6,647 & 157 & 2,187 & 330 & 56.8 & 42.1 \\
\hline $\mathrm{C}$ & 6 & Sermide-Felonica & 7,285 & 91 & 1,554 & 212 & 54.5 & 37.1 \\
\hline $\mathrm{C}$ & 7 & Castel San Giovanni & 13,725 & 312 & 6,144 & 447 & 46.9 & 27.8 \\
\hline $\mathrm{C}$ & 7 & Fiorenzuola d'Arda & 15,300 & 256 & 6,470 & 424 & 37.4 & 29.7 \\
\hline $\mathrm{C}$ & 8 & Copparo & 16,234 & 103 & 4,862 & 298 & 69.0 & 55.0 \\
\hline $\mathrm{C}$ & 8 & Goro & 3,699 & 111 & 621 & 166 & 36.8 & 14.3 \\
\hline \multirow[t]{4}{*}{$\mathrm{C}$} & 9 & Badia Polesine & 10,263 & 230 & 4,164 & 402 & 62.4 & 58.8 \\
\hline & & Total type A & 697,796 & 569 & 243,869 & 350 & 31.9 & 22.7 \\
\hline & & Total type B & 428,353 & 289 & 144,210 & 337 & 47.6 & 34.7 \\
\hline & & Total type C & 160,379 & 208 & 56,602 & 352 & 53.3 & 40.6 \\
\hline
\end{tabular}

A - provincial capital medium-sized towns, B - non-capital medium-sized towns, C - small towns.

Source: Istat data, our processing. 
With regard to the distribution of the towns in the individual provinces, there are a number of patterns. Considering MSTs only, the provinces of Asti, Lodi and Piacenza are monocentric, while all the others are bi-centric or polycentric. If we also consider small towns, only Lodi has a monocentric pattern, with the provincial capital dominating the employment area more or less covering the entire province.

The study area is characterised by another aspect: the process of erosion of Christaller's hierarchies, with a shift towards the formation of multipolar urban networks and post-metropolitan patterns, is less advanced than it is in other parts of the Po Valley megalopolis (Dematteis, Emanuel 1990; Turri 2000; Balducci et al. 2019).

The study area is the weakest link in the Po Valley megalopolis. This is confirmed by the trend of added value between 2007 and 2017: the area performed worse than the other more urbanised provinces in the regions considered, characterised by greater resilience to the two downturns that occurred in succession during the ten-year period. Only Mantua, Cremona and Asti recovered their lost added value, with 2017 levels rising above those recorded in $2007^{7}$.

The difficulties are also evident in job dynamics in the 2001-2011 and 2012-2017 periods (Table 2). There was a decline, initially slight $(-0.6 \%)$, then more sustained $(-1.5 \%)$, placing the study area on a different trajectory from its

7 The relative index number $(2007=100$, ISTAT data $)$ is 115,106 and 101 respectively, while for the regions considered, it is 111. Within the aforesaid regions, the provinces with the greatest increase are Milan (127) and Monza-Brianza (120). macro-region. However, the situations were heterogeneous at provincial level. In the first period, rates of change varied from $-10.2 \%$ (Ferrara) to $+7.3 \%$ (Piacenza); while in the second, from $-5.4 \%$ (Alessandria) to $+2.3 \%$ (Piacenza). There was always a minority group of growing provinces (four in the first period, three in the second). Alessandria, Pavia, Ferrara and Rovigo recorded a decline in the numbers of the employed in both periods examined, while the other provinces experienced continual growth or phases of alternating growth and decline.

One characteristic defining the study area is the lesser extent to which the economy has shifted to the service industry. This is highlighted by the sectoral composition of added value in 2017: although the service sector is predominant, the shares only exceed those of the reference regions in a few cases, reaching $70.3 \%$ in the provinces of Pavia and Piacenza. The industry share is in no way insignificant, nor is the share of agriculture, which has values up to 3.6 times higher than regional values (Mantua). Looking at the 39 towns selected (Table 1), it is evident how the employment structure is often very much linked to industry. Various sectors of the Italian manufacturing industry are present (textiles, leather and hides, mechanical engineering, jewellery, woodworking and food) but also heavy industry (petrochemical, metal working and pharmaceutical). In 2001, in 16 cities, the secondary sector accounted for more than half of the total numbers of the employed. Castel Goffredo, the heart of a specialised socks manufacturing district, reached as high as $72.7 \%$. In 2017 , the industry still had the lion's share in six cities: Valenza

Table 2. Employees at local units and composition of added value: provinces of the study area (2001-2017).

\begin{tabular}{|l|c|c|c|c|c|c|}
\hline \multirow{2}{*}{ Provinces } & Employees, & Change in number of employees (\%) & \multicolumn{3}{c|}{ Added value (\%), 2017 } \\
\cline { 3 - 7 } & 2017 & $2001-2011$ & $2012-2017$ & agriculture & industry & tertiary \\
\hline Asti & 56,841 & 0.7 & -3.9 & 4.8 & 29.8 & 65.4 \\
\hline Alessandria & 121,553 & -2.3 & -5.4 & 2.1 & 28.6 & 69.3 \\
\hline Pavia & 132,042 & -1.6 & -1.1 & 2.6 & 27.1 & 70.3 \\
\hline Lodi & 56,991 & 5.3 & -2.9 & 3.6 & 28.0 & 68.4 \\
\hline Cremona & 100,312 & 1.6 & 1.4 & 5.2 & 33.0 & 61.8 \\
\hline Mantua & 135,908 & -0.3 & 0.7 & 6.2 & 34.9 & 58.9 \\
\hline Piacenza & 95,094 & 7.3 & 2.3 & 3.0 & 26.7 & 70.3 \\
\hline Ferrara & 91,859 & -10.2 & -1.5 & 4.5 & 25.7 & 69.8 \\
\hline Rovigo & 66,275 & -0.7 & -5.1 & 3.7 & 28.9 & 67.4 \\
\hline Total provinces & 856,875 & -0.6 & -1.5 & 4.0 & 29.4 & 66.6 \\
\hline Total regions & $8,343,492$ & 1.3 & 1.9 & 1.7 & 28.8 & 69.5 \\
\hline
\end{tabular}

Source: Istat data, our processing. 
(a goldsmith's district) stood out from the rest, where the sector accounted for $62.3 \%$ of the total employees. While small towns clearly lead the way in terms of value, it should be noted how, in 2017, there were five non-capital MSTs whose shares of employees in the industry were over $40 \%$. All five were centres of Italian manufacturing districts (Valenza, Suzzara, Viadana, Cento and Castiglione delle Stiviere).

\section{Job dynamics}

If we examine the change in the numbers of persons employed, we are presented with a picture that is anything but unitary (Table 3). Between 2001 and 2011, the non-capital MSTs group experienced the greatest difficulties, with a significant decline in jobs $(-3.2 \%)$. Provincial capitals, on the other hand, saw a rise $(+0.9 \%)$, as did, especially small towns $(+3.9 \%)$, which even performed better than the regional data $(+1.3 \%)$. In the subsequent phase (2012-2017), the non-capital MSTs reversed the trajectory of decline by gaining employees $(+0.7 \%)$, while the small towns underwent practically zero growth $(+0.1 \%)$. The group of provincial capitals stands out, growing at more rapid rates than the others $(+1 \%)$.

In addition to aggregate data, we need to pinpoint the position of the individual towns (Fig. $1)$. There is a huge difference between the minimum and maximum rates of change in the numbers of the employed, especially for non-capital MSTs and small towns. The provincial capitals are, on the other hand, more similar to each other in terms of the values involved. In the 2001-2011 ten-year period, the growth and decline trajectories were almost equal in this group (five cases against four). The former then prevailed (seven cases). The situation of decline in the numbers of the employed prevailed among non-capital
MSTs, despite reducing over time (first nine cases, then eight). Small towns, on the other hand, are the most inhomogeneous in terms of rates of change (see the standard deviation) and evolutionary trajectories: employee figures were on the rise in 10 towns between 2001 and 2011, but the situation then reversed (eight cases of decline).

It is not easy to find trajectories that continue over time, whether for a rise or a decline in the numbers of the employed. An alternating situation is more common. However, one aspect is clear: cases of continual growth are concentrated in the central part of the study area, which is more linked to Milan and the eastern foothill area, which have driven the country's economic development, including during times of recession. Already evident between 2001 and 2011, the trend has increased over time, affecting all hierarchical levels considered. There are closer ties with the Milan metropolitan centre here, as we can see from the commuting flows for work purposes. Moreover, in the period of 2001-2019, this area recorded more rapid population growth than the other areas ${ }^{8}$. This would appear to confirm the greater viability of small and medium-sized towns close (or belonging) to metropolitan areas (Adam 2006; ESPON 2014; Meili, Mayer 2017). Overall, increasing difficulties are evident in the area to the west, where even the provincial capitals (Asti, Alessandria) have lost employees over recent years. These are areas with little interaction with the metropolitan centres, located far away from the major infrastructural corridors crossing the Po Valley megalopolis.

The data broken down by sectors of activity are interesting. There was an almost generalised decline in jobs in industry in both the time periods under review. Non-capital MSTs were

\footnotetext{
8 The provinces of Lodi, Pavia and Piacenza recorded changes of $+16.5 \%,+10.6 \%$ and $+8.9 \%$ respectively; the figure for the study area as a whole was $+5.8 \%$.
}

Table 3. Percentage change in the number of employees at local units: centres and local surroundings (20012011, 2012-2017).

\begin{tabular}{|l|c|c|c|c|}
\hline \multirow{2}{*}{\multicolumn{1}{|c|}{ Type }} & \multicolumn{2}{c|}{$2001-2011$} & \multicolumn{2}{c|}{$2012-2017$} \\
\cline { 2 - 5 } & centres & local surroundings & centres & local surroundings \\
\hline Provincial capital medium-sized towns & 0.9 & 3.5 & 1.0 & -3.0 \\
\hline Non-capital medium-sized towns & -3.2 & -3.1 & 0.7 & -4.7 \\
\hline Small towns & 3.9 & -4.9 & 0.1 & -3.7 \\
\hline
\end{tabular}

Source: Istat data, our processing. 
highly affected between 2001 and $2011(-19 \%)$, This is in line with the studies already mentioned, with peaks in Argenta (-48\%), Suzzara (-47\%), which underline the greater difficulties of MSTs Valenza $(-34 \%)$ and Vigevano $(-31 \%)$, the hubs with an industrial economic base. However, of mono-specialised manufacturing districts. the decline of industry was also significant
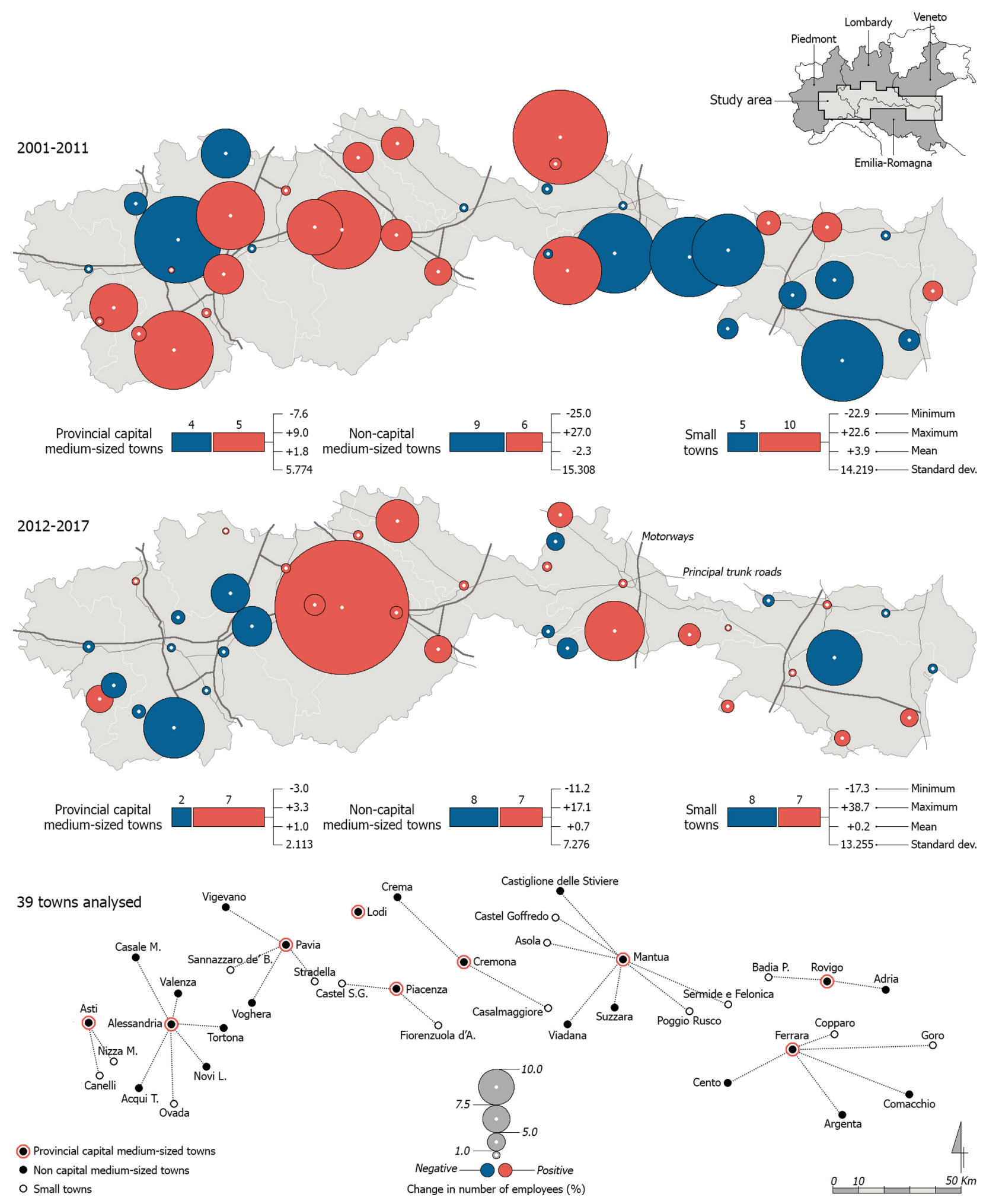

Fig. 1. Percentage change in the number of employees at local units in the 39 towns analysed (2001-2011, 2012-2017). 
elsewhere. Between 2012 and 2017 it mainly affected the small towns ( $-9 \%$ compared to $-8 \%$ in the provincial capitals and $-6 \%$ in the other MSTs). Progress of the service sector did not always offset the decline in industry. The location of urban centres is very important: proximity to the provincial capitals which offer a wide range of services, may be a problem, as demonstrated by Valenza (14 km from Alessandria), where the number of employees in the service sector fell in both periods. Another interesting case is Castel San Giovanni: benefitting from a key position in the mobility network, the municipality has attracted logistics and goods storage centres, with a considerable and continual rise in the number of employees as a result.

\section{Specialisation profiles}

To outline the functional profile of each town, the industrial and service sector activities were broken down according to the level of technological and knowledge intensity. The Eurostat classification was used, with some changes. Therefore, the following industries are considered:

- high- and medium-high-tech manufacturing industry (MI1);

- low- and medium-low-tech manufacturing industry (MI2);

- energy and mining industry (EN);

- construction (COS);

- high-tech knowledge-intensive services (KIS1);

- knowledge-intensive market services (KIS2);
- knowledge-intensive financial services (KIS3); - other knowledge-intensive services (KIS4);

- less knowledge-intensive services: wholesale and logistics (LKIS1);

- less knowledge-intensive services: other services (LKIS2).

Looking at the share of employees in various industries (Table 4), we can clearly see the significance of the manufacturing sector - in particular of the MI2 sector - in non-capital MSTs and small towns. There is a clear hierarchy in the service sector, with the provincial capitals at the top. However, some aspects are worth noting. The KIS1s, as we might expect, are concentrated in the provincial capitals. The portion of people in employment is almost twice as large as that of the other city types, but not as high as in the regional data, and decreased in the 2001-2017 period: competition with metropolitan areas is tough, primarily with Milan, where there is a high concentration of these activities, which are very sensitive to urbanisation economies. KIS2s are well-established in the capitals, where their importance has grown significantly over time. KIS3s are just as over-represented, but their share is decreasing. According also to Mayfield et al. (2005), these two activity sectors characterise MSTs in many European rural areas, reinforcing their role as centres of specialised expertise serving the surrounding areas, which are more industry-oriented. It is also evident how non-capital MSTs, in clusters, tend to maintain a more stable economic base over time, with limited fluctuations in the share of employees in various sectors. Small towns, on the other hand, have

Table 4. Percentage of employees in 10 industries broken down by level of technological and knowledge intensity: town and local surroundings $(2001,2017)$, line $=100 \%$.

\begin{tabular}{|c|c|c|c|c|c|c|c|c|c|c|c|}
\hline Area & Year & MI1 & MI2 & $\cos$ & EN & KIS1 & KIS2 & KIS3 & KIS4 & LKIS1 & LKIS2 \\
\hline \multirow{2}{*}{$\begin{array}{l}\text { Provincial capital } \\
\text { medium-sized towns }\end{array}$} & 2001 & 8.9 & 12.7 & 7.9 & 2.4 & 3.2 & 10.3 & 5.4 & 4.9 & 17.9 & 26.4 \\
\hline & 2017 & 6.7 & 8.2 & 5.6 & 2.0 & 3.1 & 14.5 & 4.3 & 10.7 & 15.5 & 29.4 \\
\hline \multirow{2}{*}{$\begin{array}{l}\text { Non-capital } \\
\text { medium-sized towns }\end{array}$} & 2001 & 12.4 & 23.4 & 10.2 & 1.7 & 1.7 & 6.6 & 3.5 & 3.2 & 15.2 & 22.1 \\
\hline & 2017 & 12.1 & 22.3 & 9.7 & 1.3 & 1.4 & 6.6 & 1.9 & 5.4 & 15.6 & 23.7 \\
\hline \multirow{2}{*}{$\begin{array}{l}\text { Small } \\
\text { towns }\end{array}$} & 2001 & 13.4 & 28.6 & 9.3 & 2.0 & 1.2 & 5.5 & 3.1 & 2.5 & 14.2 & 20.2 \\
\hline & 2017 & 9.9 & 16.4 & 6.6 & 1.8 & 1.7 & 10.8 & 3.2 & 7.1 & 14.5 & 28.0 \\
\hline \multirow{2}{*}{$\begin{array}{l}\text { Local } \\
\text { surroundings }\end{array}$} & 2001 & 14.7 & 30.3 & 11.9 & 1.2 & 0.9 & 3.4 & 1.9 & 2.3 & 13.5 & 19.9 \\
\hline & 2017 & 13.1 & 22.3 & 9.0 & 1.3 & 1.1 & 5.7 & 2.1 & 5.9 & 14.9 & 24.6 \\
\hline \multirow[t]{2}{*}{ Total provinces } & 2001 & 12.5 & 24.2 & 10.5 & 1.7 & 1.7 & 5.9 & 3.2 & 3.2 & 15.1 & 22.0 \\
\hline & 2017 & 10.4 & 17.4 & 7.8 & 1.6 & 1.8 & 9.2 & 2.8 & 7.4 & 15.4 & 26.2 \\
\hline \multirow[t]{2}{*}{ Total regions } & 2001 & 13.1 & 23.5 & 8.9 & 1.3 & 3.3 & 7.3 & 3.7 & 3.3 & 14.9 & 20.6 \\
\hline & 2017 & 10.4 & 16.1 & 7.0 & 1.4 & 3.6 & 10.5 & 3.6 & 6.6 & 14.8 & 26.2 \\
\hline
\end{tabular}

Source: Istat data, our processing. 
undergone an intensive reorganisation of their production system, which was still very much linked to industry in 2001. In 2017, this enabled them to attain higher shares of employees than non-capital MSTs across all KIS sectors. Lastly, there was a sharp increase in KIS4s in the provincial capitals. However, we need to examine the individual places: there is a different drive for the reorganisation of local economies, as demonstrated by the Finger-Kreinin (FKI) index:

$$
\mathrm{FKI}=1 / 2 \Sigma_{\mathrm{i}}\left|\mathrm{Q}_{\mathrm{it} 1}-\mathrm{Q}_{\mathrm{i} 2}\right|
$$

where:

Q - \% total employees,

i - industry,

t1, t2 - reference years.

High index values indicate a marked restructuring of the employment sector between 2001 and 2017, while low values identify more stable profiles over time (Fig. 2). This latter situation is the case of many provincial capitals - only Pavia and Mantua have an above-average FKI - while the other groups are more inhomogeneous.
The following location quotients (LQs) were calculated to measure the level of specialisation of each city and its belt in the activities considered:

$$
\mathrm{LQ}=\left(\mathrm{A}_{\mathrm{ij}} / \mathrm{A}_{\mathrm{ti}}\right) /\left(\mathrm{A}_{\mathrm{ia}} / \mathrm{A}_{\mathrm{ta}}\right)
$$

where:

A - employees,

i - industry,

$\mathrm{t}$ - total,

j - city (belt),

a - study area.

The towns have widespread specialisation $(\mathrm{LQ}>1)$ in various segments of the service sector, forming the basis of their role as poles with respect to their local surroundings (Table 5; Figs 3-4). In 2001, the industries most present were KIS3 and LKIS2: the number of cities with an LQ $>1$ in those activities were 24 and 22 respectively. KIS1 industries, which specialised 16 cities in 2001 and 14 in 2017, were more rare. The EN industry is well-established, favouring 'central' points in the territory: second only to KIS3 industries in 2017. A good number of cities (20 in

Table 5. No. of cases of specialisation (LQ>1) in 10 industries broken down by level of technological and

\begin{tabular}{|c|c|c|c|c|c|c|c|c|c|c|c|}
\hline Area & Year & MI1 & MI2 & COS & EN & KIS1 & KIS2 & KIS3 & KIS4 & LKIS1 & LKIS2 \\
\hline \multirow[t]{2}{*}{ Centres } & 2001 & 9 & 11 & 9 & 17 & 16 & 19 & 24 & 17 & 18 & 22 \\
\hline & 2017 & 7 & 11 & 9 & 21 & 14 & 20 & 22 & 17 & 11 & 17 \\
\hline \multirow{2}{*}{$\begin{array}{l}\text { Local } \\
\text { surroundings }\end{array}$} & 2001 & 20 & 29 & 26 & 7 & 2 & - & - & 6 & 4 & 5 \\
\hline & 2017 & 20 & 30 & 33 & 11 & 3 & 1 & 1 & 9 & 14 & 9 \\
\hline
\end{tabular}
knowledge intensity: centres and local surroundings (2001, 2017).

Source: Istat data, our processing.

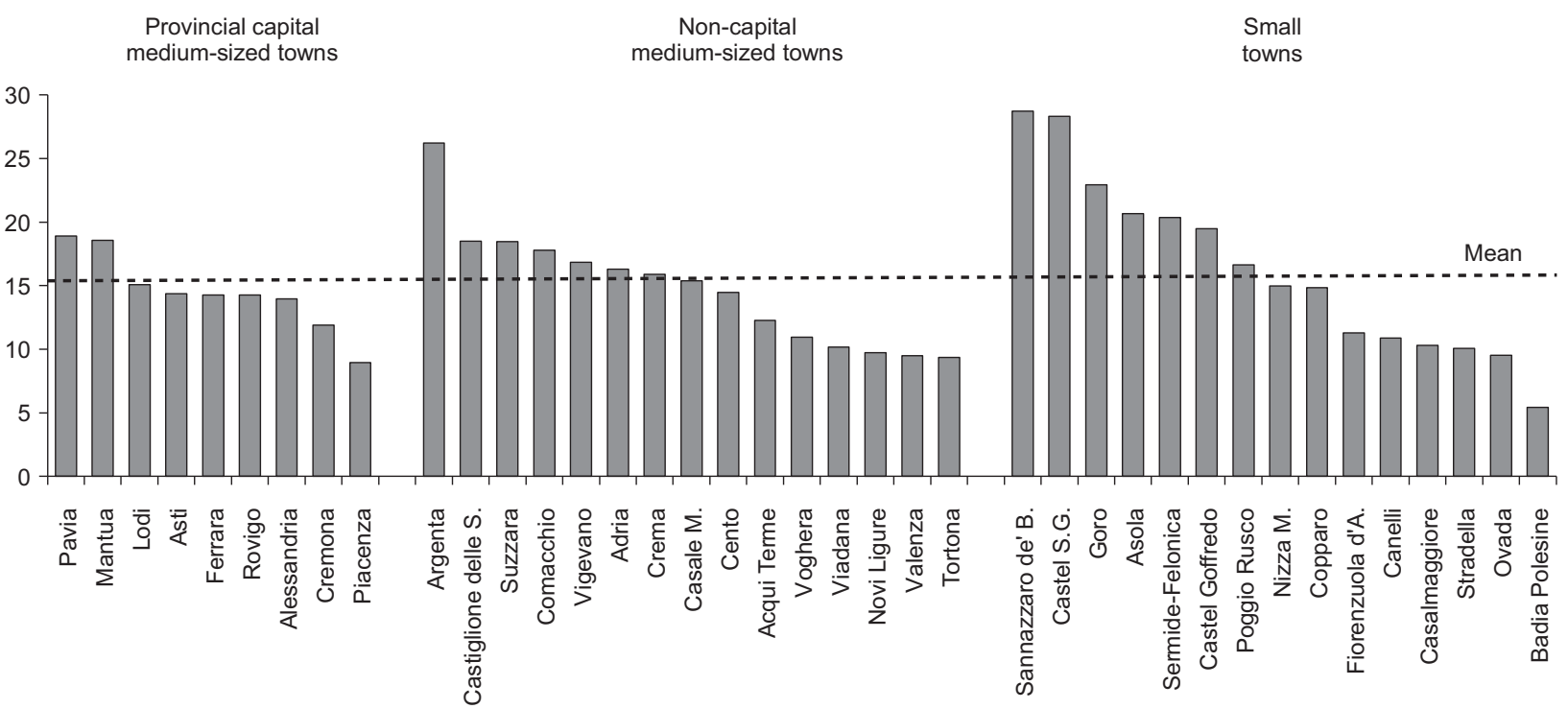

Fig. 2. Finger-Kreinin index in the 39 towns analysed (2001-2017), in descending order by type of town. 
2001

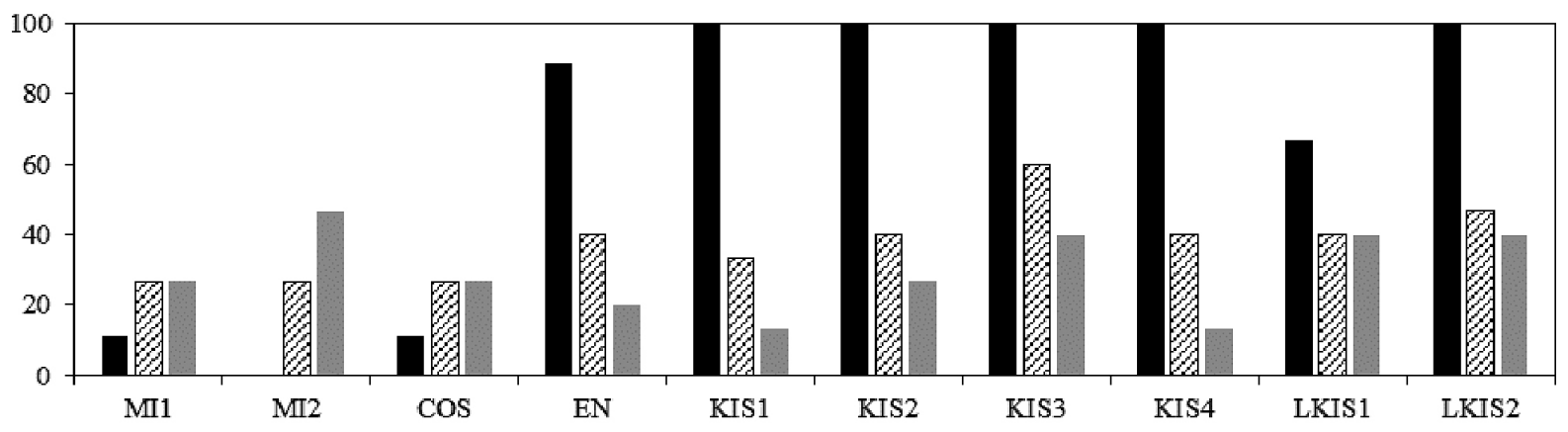

2017

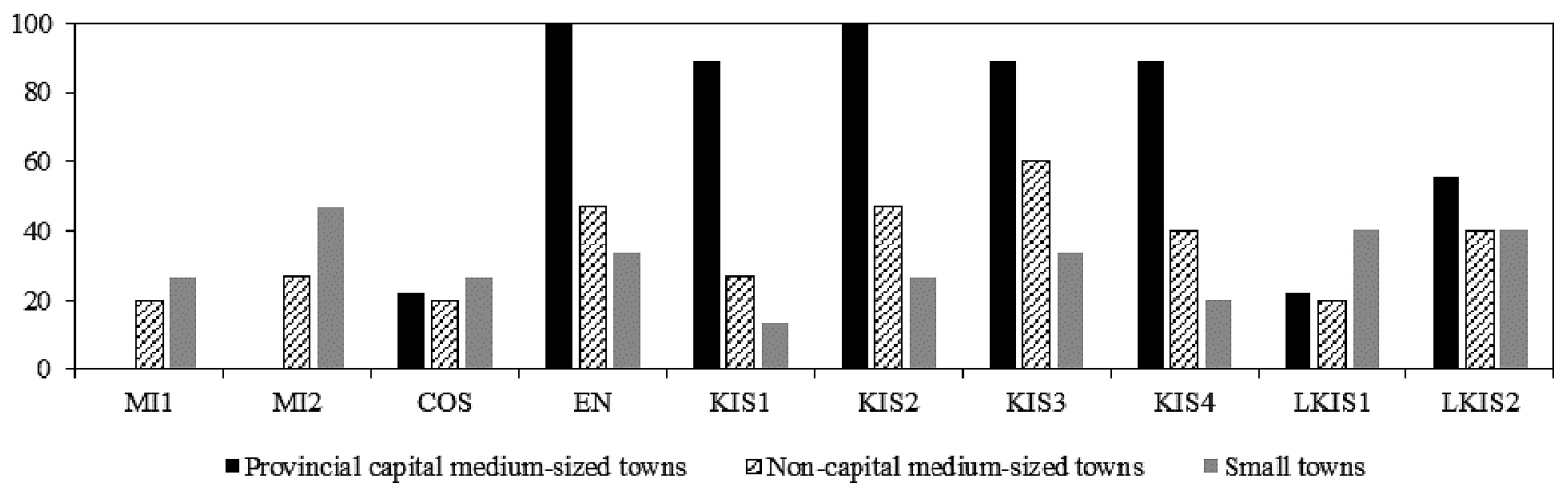

Fig. 3. Specialisation of the centres ( $L Q>1)$ in 10 industries broken down by level of technological and knowledge intensity $(2001,2017)$, percentage value.

2001
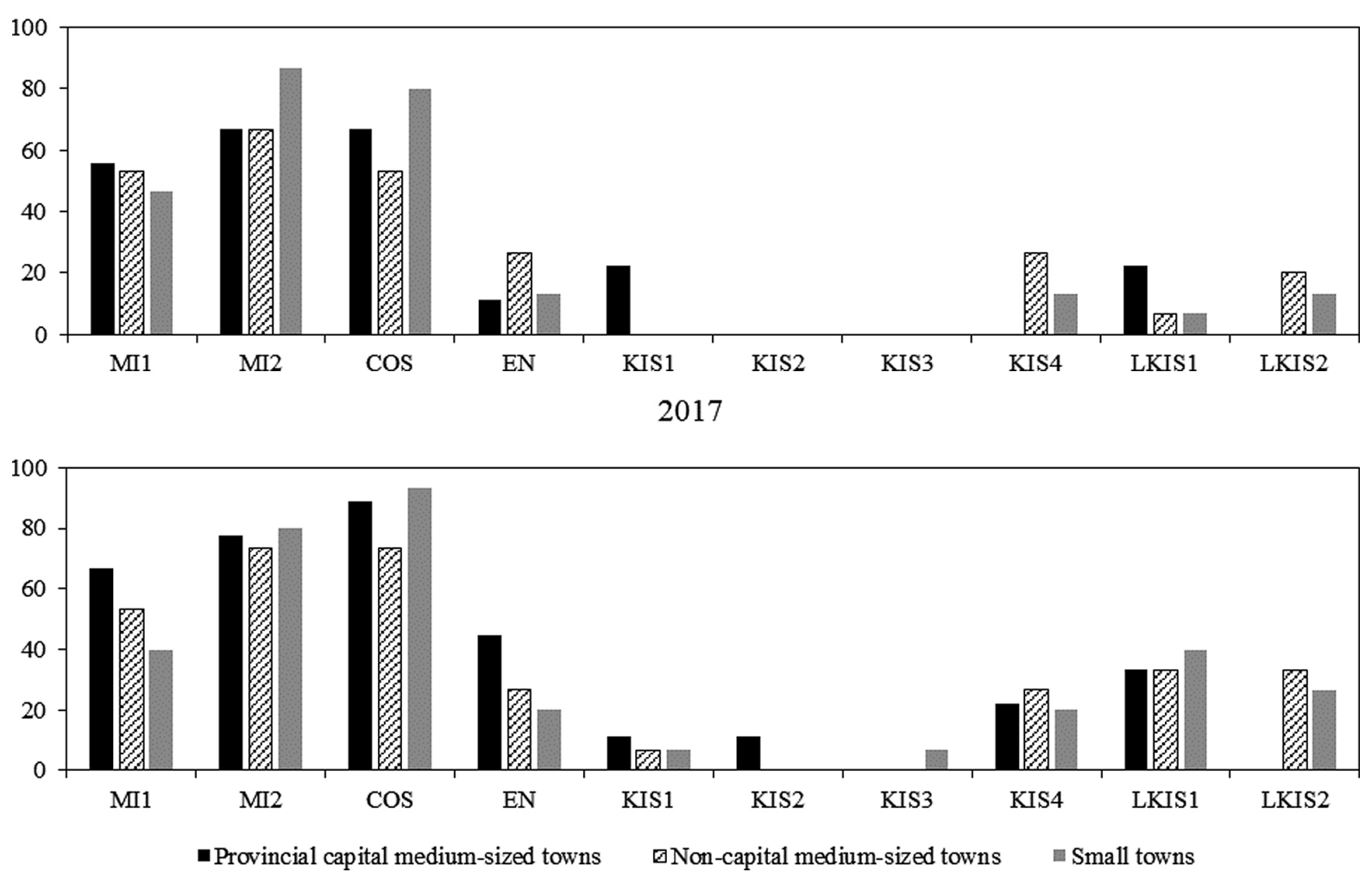

Fig. 4. Specialisation in the local surroundings (LQ>1) in 10 industries broken down by level of technological and knowledge intensity $(2001,2017)$, percentage value. 
2001, 18 in 2017) have a manufacturing character, linked to the MI2 industry in particular: many are centres of industrial districts and, in 2017, boasted an LQ $>2$ or even $>3$ (Valenza, Suzzara and Copparo). The capitals stand out for the various groups of KIS activities. Concentration levels are sometimes very high, such as for KIS1 industries in Lodi (LQ = 5.6 in 2017). This is affected by its proximity to Milan. Lodi has stepped up its specialisation in the industry, placing itself on a different trajectory from that of nearby Pavia. Here, specialisation in KIS1 industries, discernible in 2001, diminished (the LQ decreased from 2.5 to 1.8), while it increased in KIS4 industries (the LQ rose from 2.2 to 2.8), which boosted the town's residential economy. Cases of specialisation in the KIS industries are also found outside the provincial capitals, but LQ values are lower, with a few exceptions (Crema, Stradella and Sannazzaro de' Burgondi). What is also evident is the erosion of the role of provincial capitals in LKIS1 and LKIS2 industries. The decentralisation of logistics and retail has benefited the belts, which have become more specialised in these activities. Among the cities of other status, those with a key position with respect to extensive areas stand out: Castel San Giovanni is a prime example, with the LQ rising from 0.8 to 2.4 in the LKIS1 industry.

In accordance with the principles of Christaller, provincial capitals have the highest number of specialisations (on average 6.8 in 2001 and 5.7 in 2017); these are followed by other MSTs (3.8 and 3.5) and small towns (2.9 and 3.1).
However, there are exceptions to this: Stradella, for example, has high values that have remained steady over time (seven specialisations), despite its small population size. Lastly, there are many mono- and bi-specialised centres, not only among the small towns (six cases in 2017), but also among the non-capital MSTs (six cases). This is often associated with poor employment retention, which we have already discussed.

The LQs for the local surroundings of the towns - coinciding with the employment areas make up a patchwork of specialisations mirroring that of the centres: the COS, MI2 and MI1 industries and the less qualified service sector prevail. Note how the frequency of specialisations in the MI1 industry is higher around the provincial capitals; this is also the case for other industries sensitive to urbanisation economies (KIS1, KIS2, EN).

The specialisation index (SI) provides us with an overall indicator of the level of diversification of local economies:

$$
\mathrm{SI}=1 / 2 \Sigma_{\mathrm{i}}\left|\left(\mathrm{A}_{\mathrm{ij}} / \mathrm{A}_{\mathrm{ti}}\right)-\left(\mathrm{A}_{\mathrm{ia}} / \mathrm{A}_{\mathrm{ta}}\right)\right|
$$

where:

A - employees,

$\mathrm{i}$ - industry,

$\mathrm{t}$ - total,

j - city,

a - study area.

The index is 0 if the town has a sectoral composition of employees identical to that of the wider area (no specialisation); the value is 1 if

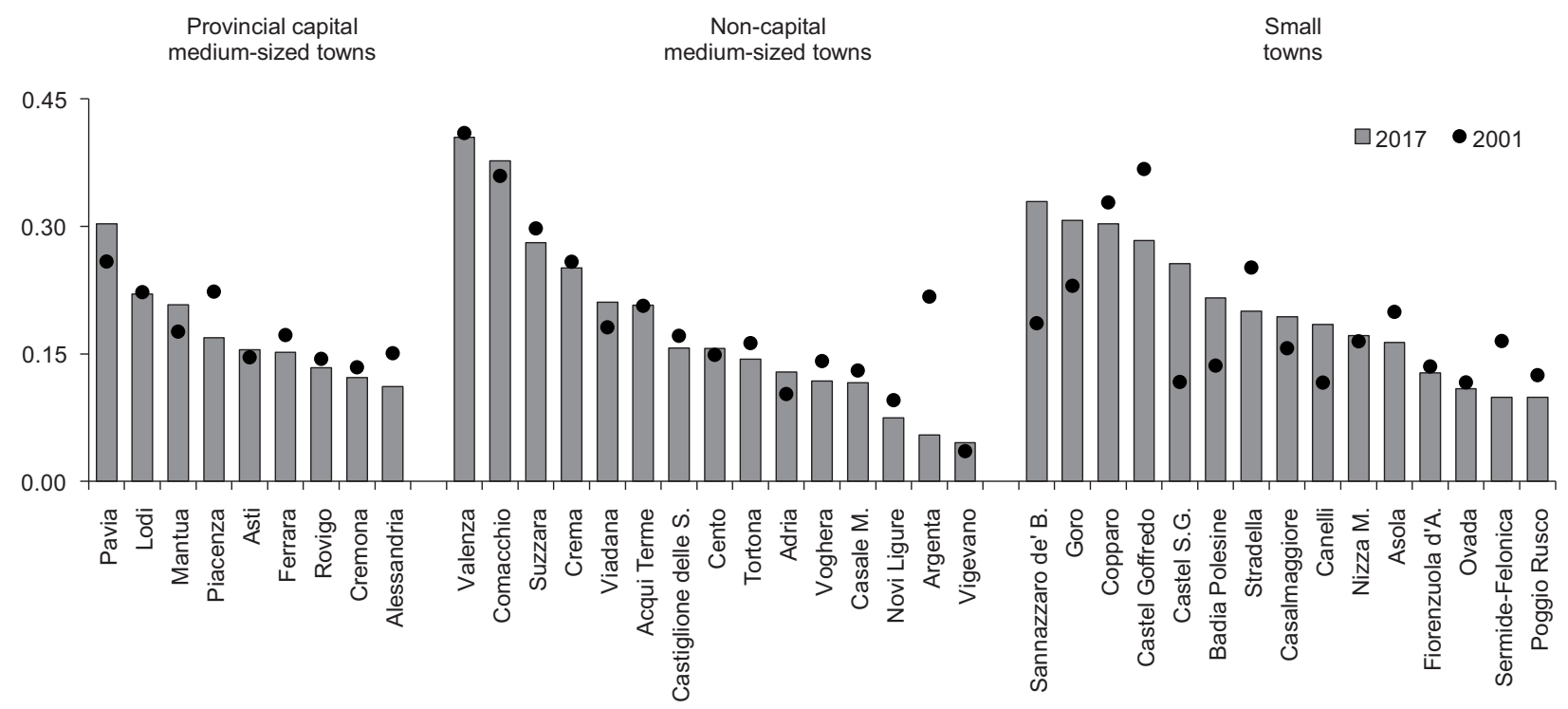

Fig. 5. Specialisation index in the 39 towns analysed $(2001,2017)$, in descending order in 2017 by type of town. 
employees are concentrated in just one industry (maximum specialisation). All the towns examined have diversified economies, as the SI is never above 0.5 (Fig. 5). The higher level of de-specialisation of the provincial capitals is confirmed, but with different values involved: in 2017, Pavia's index was more than twice as high as that of Alessandria. Variability does not spare small towns, even if they are more specialised. Non-capital MSTs are the most diverse group, with an SI varying between 0.405 (Valenza) and 0.045 (Vigevano). In the long-term (2001-2017), the drive towards the sectoral diversification of employment prevailed. There have also been quite strong opposing forces, like in Castel San Giovanni and Sannazzaro de' Burgondi: here, just a few industries have made an effort to increase the employee numbers, adopting a position of strength in local economies.

\section{Relationship between cities and local surroundings}

How has the spatial distribution of jobs changed in the study area? Which are predominant - centralisation or decentralisation processes? If it is necessary to overcome the concept of MSTs as 'free electrons', with performance reliant only on size, we need to examine the network of relations connecting each town to its local surroundings (Servillo et al. 2017). It is also interesting to understand how relationships have changed locally as a result of the 2008 economic crisis. We faced the process of production decentralisation for a long time (Razin et al. 2007), but globalisation and a knowledge-based economy have revived cities and their appeal has often increased further after 2008, prompting new territorial divisions (Monsson 2015; Holl 2018).

In this regard, it is useful to return to Table 3 to compare the employee dynamics in the towns and their respective surroundings, defined by the perimeter of the employment areas. Between 2012 and 2017, the poles of different rankings re-centralised employees. The situation was quite different before this. With regard to the provincial capitals, decentralisation was favoured by the rapid growth of jobs in the belts, while the group of small towns went in the opposite direction. A difficult situation was looming for the non-capital MSTs, on the other hand: this was the only group to experience a decrease in the number of employees, a slightly greater decrease, in fact, than that recorded in the reference surroundings. But the aggregate data conceal various situations, which need to be explored point by point. To this end, two variables were considered for each town: job dynamics and the drive towards centralisation/decentralisation, linked to the increase/decrease in the importance of the city compared to its employment area (in terms of employees). The data refer to the periods of 2001-2011 and 2012-2017. With regard to changes in the numbers of the employed, growth trajectories prevailed (21 cities in both periods, but not always the same cities). However, in a good number of cases, the dynamics were reversed. We have already focused on this aspect, which indicates heterogeneous behaviours, especially among non-capital towns. It is also clear how the drive towards the centralisation of jobs is predominant and has increased over time (from 24 to 29 cases). This trend involves capitals (from four to eight) and other MSTs (from 8 to 13). The drive towards centralisation decreased in the group of small towns (from 12 to 8), despite being prevalent.

Looking at how the variables being examined are combined in each city, the following situations can be identified (Table 6):

- centralisation and rise in the number of employees;

- centralisation and fall in the number of employees;

- decentralisation and rise in the number of employees;

- decentralisation and fall in the number of employees.

The first case indicates an expansion of the employment base of the town in conjunction with its growth compared to a poorly performing belt. This situation was already prevalent between 2001 and 2011 and spread to 20 cities in the recent phase. A growing number of capitals have followed this trajectory (first four, then six). Although we also find many centres of other ranking, it should be noted how the incidence of the trajectory reduced over time among small towns (from nine to seven cases), unlike in other groups. This trajectory was especially active in the various service industries already 
considered. Frequency was high for small towns, even in industrial activities, a long-lasting characteristic.

The town became stronger in the second case, but only relatively so, due to a smaller decrease in the number of employees than in the local surroundings. The scenario is one of poor job retention, even though the centre performs better than the employment area. This situation involved a growing number of towns (from six to nine), including two provincial capitals (Asti and Alessandria) in the most recent phase. Once again, the small towns bucked the trend, becoming the least affected by these dynamics (first three cases, then one). On industry level, this is characteristic of industrial activities, while it is sporadic in service industries.

The third case is very interesting: the city experiences a rise in the number of people employed, but this is counteracted by an even more vibrant belt, so that the drive for decentralisation prevails. This is definitely the least common case and was only found in one capital in the most recent phase: Mantua. However, looking at what happens in various activity industries, this situation is certainly not rare: it characterises various sectors of the service industry, especially in towns close to Milan, which have very dynamic and populated belts.

Finally, the fourth case indicates a weakening of the town compared to its surroundings, resulting from a more marked decline in the number of employees compared to the belt, or a decline in contrast to the growth dynamics of the belt. This situation is common. It affected 12 towns in the first period, almost all medium-sized, four of which capitals. The cases then decreased to nine, associated mainly with small towns. Only two MSTs were in this situation in the recent phase (Novi Ligure, Voghera). At the level of individual activities, this situation is more common in the industrial sector and in some service sectors. This is also the case for the provincial capitals: their densely populated belts have attracted service industries and given greater 'protection' to employment in manufacturing and construction.

It is certainly not surprising to find differences between cities. They have a different hierarchical level and differences are inevitable. What is significant is that even within one single group of cities, different dynamics are at play, rooted in local history and geography. A unitary description is not possible, especially for non-capital MSTs and small towns.

As shown in Table 6, in the long-term (20012017), 29 cities became stronger than their employment areas, attracting growing numbers of employees. The repolarisation process is also visible on a provincial scale: as many as 26 cities became more important. All the capitals, apart from Asti, grew stronger within the provinces, while the situation was more variegated for other towns, especially for the small ones, which only grew stronger than their province in eight cases. The share of the centres is variable, but it should be noted how it often tends to grow significantly. On a local scale (employment area), the change is between $5 \%$ and $10 \%$ in nine towns, and above $10 \%$ in 10 towns. On a wider scale (province), as many as 15 towns experienced changes of above $10 \%$.

\section{Conclusions}

MSTs are precious links between urban and rural, and local and global. They are also elusive entities that are very different from one another: they create unity in variety. Marked differences can also be seen within the study area, both in the dynamics of the numbers of the employed and in the specialisation profiles and power relations with their respective employment areas. Besides belonging to the same territorial area with a low population density, the history of each town is rooted locally and makes a unitary narrative impossible. The study area takes the form of a kind of 'inner periphery': although it is located in the Po Valley megalopolis, one of the most developed and dynamic macro-regions in Europe, it is largely characterised by underperformance compared to the densely urbanised provinces surrounding it, which are home to metropolitan areas that were more resilient to the Great Recession. The 39 towns considered reflect this difficult situation, which is evident in the trends of added value and jobs. The provincial capitals have performed better, especially in the most recent phase (2012-2017). Thanks to their size, they enjoy larger agglomeration economies and have a diverse economic fabric, which has enabled them to be resilient in the face of recession shock. 
However, there have been situations of declining numbers of employees (in the recent phase: Asti, Alessandria). The non-capital MSTs and especially small towns grapple with the greatest difficulties. As is the case in other countries, this is more evident where the economic base is more closely linked to the industrial sector.

There is a division between towns of the same ranking, which have followed different trajectories. However, the overall picture is clearer than it appears at first glance: performance is better at all hierarchical levels in the central part of the study area. Here, despite laying claim to an employment area of their own, the MSTs are within the sphere of influence of Milan, a buzzing global city that drove the economic recovery of Italy after the Great Recession. Proximity to and busy links with the city (as demonstrated by the commuting flows) have facilitated the growth of the surrounding medium-sized and small towns. In particular, this enabled Piacenza and Lodi to enjoy high rates of growth in employees in both periods examined, which is rare in the study area. We did not conduct a systematic study of the networks of relations of the towns. However, those towns located within the magnetic field of a city appear to perform better, in line with the other studies on other European countries already mentioned. Specialisation is important, too: logistics and advanced services guarantee that towns will perform well, whatever their size.

Another clear aspect is the drive towards the centralisation of employees, which increased in the 2012-2017 period. This is more evident for the provincial capitals and other MSTs, while small towns have more opposing dynamics. Repolarisation is often only relative, caused by a smaller decrease in employees in the city than in the employment area: as many as six non-capital MSTs out of 15 found themselves in this situation in the recent phase. The provincial capitals, on the other hand, are almost all absolute centralisers: they increased in importance with a rise in the number of people employed. The drive towards centralisation confirms the role of centres of development played by the MSTs in rural areas, which appears to intensify during downturns. However, widening gaps are anticipated between territories.

In summary, four aspects have emerged:

1. the strength of provincial capital MSTs;
2. the crisis of more industry-specialised towns;

3. the better performance of towns close to metropolitan centres (in particular to Milan),

4. the gradual centralisation within employment areas.

Much of the study area has been hit hard by the SARS-CoV-2 pandemic that broke out in March 2020. Now we have the problem of the revival: the different specialisation profile of the towns and their position - whether or not one of strength - attained before the pandemic will affect recovery prospects, along with many other factors.

The research could be expanded on in two areas. First of all, we could study in greater detail the networks of relations of the MSTs and their evolution over time, to understand how these have affected local development trajectories (along the lines of the ESPON 2014 study). Secondly, it would be useful to consider other case studies, for example, in the south of Italy, where there is a different settlement structure, which influences the identification and roles of the MSTs in urban networks.

\section{References}

Adam B., 2006. Medium-sized cities in urban regions. European Planning Studies 14(4): 547-555. DOI 10.1080/09654310500421220.

Balducci A., Fedeli V., Curci F. (eds), 2019. Post-metropolitan territories. Looking for a new urbanity. Routledge, London and New York.

Bartaletti F., 2015. Città metropolitane e aree metropolitane. Il disegno politico e l'approccio scientifico (Metropolitan cities and metropolitan areas. The political project and the scientific approach). Rivista Geografica Italiana 122(4): 389-400.

Bell D., Jayne M., 2009. Small cities? Towards a research agenda. International Journal of Urban and Regional Research 33(3): 683-699. DOI 10.1111/j.1468-2427.2009.00886.x.

Bolton T., Hildreth P., 2013. Mid-sized cities: Their role in England's economy. Centre for Cities, London.

Brunet R., 1997. Territoires de France et d'Europe. Raisons de géographe. Belin, Paris.

Burgalassi D., Iommi S., Marinari D., 2016. Dimensione e offerta funzionale nella crescita urbana. Alcune evidenze nel periodo 2001-2011. (City size, urban functions and growth. Some empirical evidence for Italy 2001-2011). Scienze Regionali 15(2): 37-60. DOI 10.3280/SCRE2016002003.

Camagni R., Capello R., Caragliu A., 2015. The rise of second-rank cities: What role for agglomeration economies? European Planning Studies 23(6): 1069-1089. DOI 10.1080/09654313.2014.904999.

Cattan N., Saint-Julien T., 1999. Quels atouts pour les petites et moyennes villes en Europe occidentale? L'In- 
formation Géographique 63(4): 158-164. DOI 10.3406/ingeo.1999.2655.

CGET, 2018. Regards croisés sur les villes moyennes. Des trajectoires diversifiées au sein des systèmes territoriaux. La Documentation française, Paris.

Champion T., Townsend A., 2013. Great Britain's second-order city regions in recessions. Environment and Planning $A$ 45(2): 362-382. DOI 10.1068/a45100.

Clayton N., Morris K., 2010. Recession, recovery and medium-sized cities. The Work Foundation, London.

Cori B., Cortesi G., Costa M., Da Pozzo C., Formentini U., 1978. Il ruolo delle città medie e piccole nella rete urbana dell'Italia settentrionale (The role of small and medium-sized towns in the urban network of Northern Italy). In: Muscarà C. (ed.), Megalopoli mediterranea (Mediterranean megalopolis). Franco Angeli, Milano: 159-170.

Cox E., Longlands S., 2016. The role of small and medium-sized towns and cities in growing the northern powerhouse. Institute for Public Policy Research, Manchester.

Czapiewski K., Bański J., Górczyńska M., 2016. The impact of location on the role of small towns in regional development: Mazovia, Poland. European Countryside 8(4): 413-426. DOI 10.1515/euco-2016-0028.

David Q., Peeters D., Van Hamme G., Vandermotten C., 2013. Is bigger better? Economic performances of European cities, 1960-2009. Cities 35: 237-254. DOI 10.1016/j. cities.2013.07.011.

Dematteis G., Emanuel C., 1990. Reti urbane minori e deconcentrazione metropolitana nella Padania centro-occidentale (Smaller urban networks and metropolitan deconcentration in central-western Po Valley). In: Martellato D., Sforzi F. (eds), Studi sui sistemi urbani (Studies on urban systems). Franco Angeli, Milano: 233-261.

De Roo P. (ed.), 2007. Les villes moyennes françaises. Enjeux et perspectives. La Documentation française, Paris.

Demazière C., 2017. Small and medium-sized towns: A research topic at the margins of urban studies?. In: Hamdouch A., Nyseth T., Demazière C., Førde A., Serrano J., Aarsæther N. (eds), Creative approaches to planning and local development. Insights from small and medium-sized towns in Europe. Routledge, London and New York: 22-35.

Dijkstra L., Garcilazo E., McCann P., 2013. The economic performance of European cities and city regions: Myths and realities. European Planning Studies 21(3): 334-354. DOI 10.1080/09654313.2012.716245.

Dijkstra L., Garcilazo E., McCann P., 2015. The effects of the global financial crisis on European regions and cities. Journal of Economic Geography 15(5): 935-949. DOI $10.1093 / \mathrm{jeg} / \mathrm{lbv032}$.

EC, 2008. Green paper on territorial cohesion. Turning territorial diversity into strength. $\mathrm{COM}(2008) 616$ final. Brussels.

Erickcek G.A., McKinney H., 2006. "Small cities blues:" Looking for growth factors in small and medium-sized cities. Economic Development Quarterly 20(3): 232-258. DOI 10.1177/0891242406290377.

Escudero Gómez L.A., García González J.A., Martínez Navarro J.M., 2019. Medium-sized cities in Spain and their urban area within national network. Urban Science 3(1): 1-15. DOI 10.3390/urbansci3010005.

Escudero Gómez L.A., Somoza Medina J., 2010. Medium-sized cities: Polycentric strategies vs the dynamics of metropolitan area growth. The Open Urban Studies Journal 3(2): 2-13. DOI 10.2174/1874942901003010002.

ESPON, 2006. The role of small and medium-sized towns (SMESTO). Final Report. ESPON, Luxembourg.
ESPON, 2014. TOWN. Small and medium-sized towns in their functional territorial context. Final Report. ESPON, Luxembourg.

Eurostat, 2016. Urban Europe. Statistics on cities, towns and suburbs. EU Publications, Luxembourg.

Faggian A., Gemmiti R., Jaquet T., Santini I., 2018. Regional economic resilience: The experience of the Italian local labor systems. Annals of Regional Science 60(2): 393-410. DOI 10.1007/ s00168-017-0822-9.

Ganau Casas J., Vilagrasa Ibarz J., 2003. Ciudades medias en España: posición en la red urbana y procesos urbanos recientes. Mediterráneo Económico 3: 37-73.

Garrido Cumbrera M., Rodríguez Mateos J.C., López Lara E., 2016. El papel de las ciudades medias de interior en el desarrollo regional. El caso de Andalucía. Boletin de la Asociacíon de Geógrafos Españoles 71: 375-395. DOI 10.21138/ bage.2287.

Glaeser E., 2011. Triumph of the city. How our greatest invention makes us richer, smarter, greener, healthier, and happier. Penguin Random House, New York.

Hamdouch A., Demazière C., Banovac K., 2017a. The socio-economic profiles of small and medium-sized towns: Insights from European case studies. Tijdschrift voor Economische en Sociale Geografie 108(4): 456-471. DOI 10.1111/ tesg.12254.

Hamdouch A., Nyseth T., Demazière C., Førde A., Serrano J., Aarsæther N. (eds), 2017b. Creative approaches to planning and local development. Insights from small and medium-sized towns in Europe. Routledge, London and New York.

Henderson V., 1997. Medium size cities. Regional Science and Urban Economics 27(6): 583-612. DOI 10.1016/S01660462(96)02169-2.

Holl A., 2018. Local employment growth patterns and the great recession: The case of Spain. Journal of Regional Science 58(4): 837-863. DOI 10.1111/jors.12392.

IFEL, 2019. Il potenziale delle città medie nel sistema Italia (The potential of medium-sized towns in the Italian system). IFEL, Roma.

Jones A., Clayton N., Tochtermann L., Hildreth P., Marshall A., 2009. City relationships: Economic linkages in Northern city regions. Centre for Cities, London.

Kaufmann D., Wittwer S., 2019. Business centre or bedroom community? The development of employment in small and medium-sized towns. Regional Studies 53(10): 14831493. DOI: 10.1080/00343404.2019.1585529.

Knox P.L., Mayer H., 2013. Small town sustainability. Econom$i c$ social, and environmental innovation. Birkhauser, Basel.

Kunzmann K.R., 2010. Medium-sized towns, strategic planning and creative governance. In: Cerreta M., Concilio G., Monno V. (eds), Making strategies in spatial planning: Knowledge and values. Springer, Dordrecht: 27-45.

Lazzeroni M., 2020. Industrial decline and resilience in small towns: Evidence from three European case studies. Tijdschrift voor Economische en Sociale Geografie 111(2): 182195. DOI 10.1111/tesg.12368.

Lemmi E., 2012. Dinamiche e processi nella geografia delle città in Italia. Quadro storico di fine millennio (Dynamics and processes in the geography of cities in Italy. Historical picture of the end of the millennium). Franco Angeli, Milano.

Mainardi R., 1997. L'Italia delle regioni. Il Nord e la Padania (Italy of the regions. The North and the Po Valley). Bruno Mondadori, Milano.

Marques da Costa E., 2002. Ciudades médias: contributos para a sua definição, Finisterra, 37(74): 101-128. DOI 10.18055/Finis1592. 
Mayfield L., Courtney P., Tranter R., Jones P., 2005. The role of small and medium-sized towns in rural development. Final Report. Centre for Agricultural Strategy, Reading.

Mecenate 90, 2020. L'Italia policentrica. Il fermento delle città intermedie (Polycentric Italy. The ferment of intermediate cities). Franco Angeli, Milano.

Meijers E.J., Burger M.J., Hoogerbrugge M.M., 2016. Borrowing size in networks of cities: City size, network connectivity and metropolitan functions in Europe. Papers in Regional Science 95(1): 181-199. DOI 10.1111/pirs.12181.

Meili R., Mayer H., 2017. Small and medium-sized towns in Switzerland: Economic heterogeneity, socioeconomic performance and linkages. Erdkunde 71(4): 313-332. DOI 10.3112/erdkunde.2017.04.04.

Monsson C.K., 2015. Resilience in the city-core and its hinterland: The case of Copenhagen. Local Economy 30(2): 191-214. DOI 10.1177/0269094215573415.

Nadou F., 2010. La notion de "villes intermédiaires", une approche différenciée du rôle des villes moyennes: entre structuration territoriale et spécificités socio-économiques. Online: halshs.archives-ouvertes.fr/ halshs-00596204 (accessed: 30 July 2020).
Razin E., Dijst M., Vázquez C. (eds), 2007. Employment deconcentration in European metropolitan areas. Market forces versus planning regulations. Springer, Dordrecht.

Santamaria F., 2000. La notion de "ville moyenne" en France, en Espagne et au Royaume-Uni. Annales de Géographie 109(613): 227-239. DOI 10.3406/geo.2000.1866.

Servillo L., Atkinson R., Hamdouch A., 2017. Small and medium-sized towns in Europe: Conceptual, methodological and policy issues. Tijdschrift voor Economische en Sociale Geografie 108(4): 365-379. DOI 10.1111/tesg.12252.

Sýkora L., Mulíček O., 2017. Territorial arrangements of small and medium-sized towns from a functional-spatial perspective. Tijdschrift voor Economische en Sociale Geografie 108(4): 438-455. DOI 10.1111/tesg.12249.

Turri E., 2000. La megalopoli padana (The Po Valley megalopolis). Marsilio, Venezia.

UCLG, 2017. Co-creating the urban future. The agenda on metropolises, cities and territories. UCLG, Barcelona.

Vaishar A., Zapletalová J., 2009. Small towns as centers of rural micro-regions. European Countryside 1(2): 70-81. DOI 10.2478/v10091/009-0006-4. 